The International Journal of Indian Psychology

ISSN 2348-5396 (e) | ISSN: 2349-3429 (p)

Volume 5, Issue 1, DIP: 18.01.119/20170501

DOI: $10.25215 / 0501.119$

http://www.ijip.in | October-December, 2017

Original Research Paper

\title{
Cognitive Skill Development Training for People with Traumatic Brain Injury
}

\author{
D. Vasantha Prabha $^{1 *}$, Sarah Manickaraj ${ }^{2}$
}

\section{ABSTRACT}

The objective of the study is to examine the effectiveness of Cognitive Skill Development Training among People with Traumatic Brain Injury. A sample of 90 People with Mild Traumatic Brain Injury were chosen by purposive sampling from Neurological Departments. Post-Concussion Syndrome questionnaire and Cognitive Disability scale was administered. The research was conducted in four phases: (1) Baseline assessment (2) Pre-test (3) Cognitive Skill Development Training and (4) Post-test. To find out the effectiveness of Cognitive Skill Development Training, paired "t” test was computed. The findings revealed that Cognitive Skill Development Training among People with Mild Traumatic Brain Injury significantly improved cognition and adaptive behavior.

Keywords: Cognitive Skill, Development Training, Traumatic Brain Injury

According to Kay (1986) “Trauma in which the Brain is struck, or moves violently, resulting in a transient alternation of consciousness, for which the patient is hospitalized for a relatively brief period, usually a few days, followed by discharge with no prescription for formal rehabilitation. Post-Concussive Syndrome prevail from months to years following injury due to both physical and psychological reasons. The symptoms are very severe and affect the activities of daily living (ADLs) or an inability to return take up employment before Traumatic Brain Injury. Though people are affected by these difficulties are less in number as time progresses some people experience symptoms even after their injury for a long duration though brain scans (i.e., MRIs, CT, EEG) are completely normal. (Jotwani \& Harmon, 2010).

A person with Cognitive Disability have difficulty with one or more types of mental tasks than the able-bodied. Cognitive Disability refers to a significantly sub-average intellectual functioning that results concurrently with deficits in adaptive behavior and that seriously affects intellectual performance. Cognitive impairment occurs when thought processes are

\footnotetext{
${ }^{1}$ Ph.D. Research Scholar, Dept. of Psychology, Manonmaniam Sundaranar University, Tirunelveli, Tamilnadu, India

${ }^{2}$ Associate Professor, Dept. of Psychology, Presidency College, Chennai, Tamilnadu, India

*Responding Author

(C) 2017 Prabha V \& Manickaraj S; licensee IJIP. This is an Open Access Research distributed under the terms of the Creative Commons Attribution License (www.creativecommons.org/licenses/by/2.0), which permits unrestricted use, distribution, and reproduction in any Medium, provided the original work is properly cited.
} 


\section{Cognitive Skill Development Training for People with Traumatic Brain Injury}

incoherent like loss of higher reasoning, forgetfulness, learning disabilities, concentration difficulties, decreased intelligence, and other reductions in mental functions.

The objective of Cognitive Skill Development Training after Brain injury is to enhance the potentiality to process, interpret information and to improve ability to carry out mental activities. Cognitive Rehabilitation is beneficial when administered as multidisciplinary or interdisciplinary approach.

Christensen et al., (2008) established that steep recovery curves were recognized in memory, speeded executive function, verbal concept, and manual dexterity in relation to untimed assessments of executive function and word knowledge. Fleminger (2008) confirmed good rehabilitation minimizes the risk of psychiatric sequelae, but specific psychological and pharmacological treatments may be needed. Londos et al., (2008) identified rehabilitation program commonly used in Traumatic Brain Injury can aid Mild Cognitive Impaired patients to develop compensatory memory strategies that improve their cognition, occupational performance, and quality of life. Bouwens et al., (2009) specified the feasibility of clinical experiences with goal attainment scaling when used for the evaluation of cognitive rehabilitation in people with acquired brain injury. Slomine et al., (2009) reviewed the theoretical and empirical literature on cognitive restoration in a variety of treatment domains including attention, memory, independent neglect, speech, language, executive functioning, and family participation and education. De Norena et al., (2010) recommended the neuropsychological rehabilitation in patients with acquired brain injury. Amanda et al., (2014) established that Cognitive rehabilitation is a suitable treatment option for Traumatic Brain Injury patients with cognitive deficits. Basford Jeffrey et al., (2015) concluded that focused efforts at cognitive training appear potentially helpful for people with acquired brain injury. Ahmed Saeed et al., (2017) revealed the options to improve the treatment and rehabilitation following Traumatic Brain Injury in future.

\section{Objective Of The Study}

- To find out the effectiveness of Cognitive Skill Development Training to improve Cognition and adaptive behavior among People with Mild Traumatic Brain Injury.

\section{Hypothesis}

- People with Mild Traumatic Brain Injury would not significantly differ in Cognitive Disability - Cognition and Adaptive Behaviour after the Cognitive Skill Development Training.

\section{METHODOLOGY}

\section{Sample:}

Sample comprised of 90 People with Mild Traumatic Brain Injury treated as out patients were chosen randomly from neurological departments from various Private Hospitals in Chennai city. Prior approval from the hospital and informed consent was obtained from the chosen sample who agreed to participate in the study. Confidentiality was maintained. 


\section{Cognitive Skill Development Training for People with Traumatic Brain Injury}

\section{Inclusion criteria:}

People with Mild Traumatic Brain injury who have undergone concussion type of Brain Injury, aged above 18 years and below 56 years, Men and Women, School educated, Nongraduates and Graduates, belonging to Low, Middle and High Income Group with a Duration of Post Injury ranging from 01 - 03 months, 03 - 06 months, 06 - 09 months were chosen for the study.

\section{Exclusion criteria:}

People with Severe Traumatic Brain injury who have undergone Contusion, CoupContrecoup, Diffuse Axonal, Penetration, aged below 18 years and above 56 years, Transgender, both Uneducated and Illiterates with a Duration of post injury over 09 months were not chosen for the study.

\section{Instruments}

1. Post-Concussion Syndrome Questionnaire by Vasantha Prabha and Sarah Manickaraj (2015) was administered on the People with Traumatic Brain Injury to test the severity of Brain injury. Based on this tool, only People with Mild Traumatic Brain Injury were chosen for the study. The questionnaire proved to be rationalised after including the main factors affecting People with Mild Traumatic Brain Injury. Initially the tool was developed with 15 items; later 05 items were removed because of the ambiguity of the statements in reliability analysis. The Cronbach alpha value is 0.77 . The test-retest score is 0.81 .

Scoring: The 10 item self-report questionnaire that measures the severity of common Post-concussion symptoms on a 4 point Likert scale ranging from 1 to 4 (1 - strongly disagree, 2 - Disagree, 3 - Agree, 4 - strongly agree) was calculated by adding all items. High score (30 - 40) denotes severity of post concussive symptoms and low score below 30 denotes mild symptoms of Post-concussion encountered by the People With Mild Traumatic Brain Injury, based on which they were chosen for the present study.

2. Cognitive Disability scale: The scale was applied with a view to assess the level of cognition and adaptive behaivour among People With Mild Traumatic Brain Injury. This scale was developed initially with 20 items under two dimensions Cognition and Adaptive Behavior. Only 15 items were found to be consistent with Cronbach alpha value 0.81 . The test-retest score is 0.88 .

Scoring: This scale consists of (10) constructs under cognition ' 1 'score for every correct answer and ' 0 ' for incorrect answer and (05) constructs under adaptive behavior ' 1 ' for behavior present and ' 0 ' for absent. A score above 05 and 02 in Cognition and Adaptive Behavior denote better Cognition and good Adaptive Behavior respectively. Score less than 05 and 02 indicates poor cognition and less adaptive behavior.

Purpose of Testing: To ensure appropriate treatment, interventions were designed for People with Mild Traumatic Brain Injury and the primary role of the neuropsychological evaluation is to assess the implications of people's capacity to return back to normal activities. 


\section{Procedure}

Phase I - Baseline Assessment: The base line assessment was conducted using Post-Concussion Syndrome Questionnaire and Cognitive Disability Scale. This screening tool diagnoses the level of cognitive disability among People with Traumatic Brain Injury. Thus only people with Mild Traumatic Brain Injury were chosen for the present study.

Phase II - Pre-Test: In pre-test, the data was collected in two sessions. The sample were instructed carefully about the psychological tests and doubts were clarified whenever necessary. The responses were recorded for the tests on a separate printed answer sheet and the booklet was collected. It took approximately three months to collect the data from People with Mild Brain injury.

Phase III - Cognitive Skill Development Training: People with Mild Traumatic Brain Injury were given specially devised Cognitive Skill Development Training to enhance their cognition and adaptive behaviour, in an out-patient Neurobehavioral Rehabilitation Centre. The training lasted for about four months with 18 hours session. Cognitive Skill Development Training comprises of games which were administered to People with Mild Traumatic Brain Injury to reduce their Cognitive Disability. This training is carried out through a board game which consists of 16 levels under each variable. The levels are based on progressive method. This game is played on a specially designed rectangular shaped board which contains six colors (red, green, yellow, blue, orange and purple). 16 levels of game sheets containing various brain stimulating puzzles are were used to play this game. It was designed to develop skills in visual discrimination, pattern awareness, sorting, classifying, sequencing, number sense and letter recognition.

\section{Concentration and Perception Games}

\section{Concentration \& Perception Games}

\begin{tabular}{|l|l|l|l|}
\hline Playground & Sailing trip & Birthday presents & Hiding together \\
\hline Hopscotch & Red racing cars & Silhouette & American Indians \\
\hline Animals racing & Walking & Ride together & Birthday cakes \\
\hline Sand castle & Funny figures & Swimming pool & Tins and balls \\
\hline
\end{tabular}

Phase IV - Post-Test: Following the Cognitive Skill Development Training, the Post-Test was conducted to the sample after a gap of 30 days. Cognitive Disability scale was administered again as these constituted Post-Test Scores, to study the effectiveness of Cognitive Skill Development Training.

\section{Statistical Analysis}

Paired t-test was used to find out impact of Cognitive Skill Development Training among People with Mild Traumatic Brain Injury in this study.

Table 1 - shows Pre and Post Assessment Scores

\begin{tabular}{|l|l|l|l|l|l|l|l|}
\hline $\begin{array}{l}\text { Sl. } \\
\text { No. }\end{array}$ & Dimensions & $\begin{array}{l}\text { Cognitive Skill } \\
\text { Development }\end{array}$ & $\mathbf{n}$ & Mean & SD & t-value \\
\cline { 1 - 7 } & \multirow{2}{*}{ Cognition } & Before & 90 & 4.73 & 1.81 & $12.55^{* *}$ \\
\cline { 3 - 6 } & & After & 90 & 6.43 & 1.96 & \\
\hline
\end{tabular}




\begin{tabular}{|l|l|l|l|l|l|l|l|}
\hline $\begin{array}{l}\text { Sl. } \\
\text { No. }\end{array}$ & Dimensions & $\begin{array}{l}\text { Cognitive } \\
\text { Development }\end{array}$ & Skill & $\mathbf{n}$ & Mean & SD & t-value \\
\cline { 1 - 6 } 2. & $\begin{array}{l}\text { Adaptive } \\
\text { Behavior }\end{array}$ & Before & 90 & 2.48 & 0.73 & $8.25^{* *}$ \\
\cline { 3 - 6 } & & After & 90 & 3.37 & 0.62 & \\
\hline
\end{tabular}

* Significant at 0.01 level

\section{RESULTS}

Table - 1, shows that Pre-Test and Post-Test scores of Cognition and Adaptive Behaviour in Cognitive Disability. The Pre-Test and Post-Test mean score of Cognition is 4.73 and 6.43 respectively and the t-value is 12.55 . The Pre-Test and Post-Test mean score of Adaptive Behaviour is 2.48 and 3.37 respectively and the t-value is 8.25. It indicates that Post-Test scores of Cognition and Adaptive Behavior is significant at 0.01 level. Hence the hypothesis "People with Mild Traumatic Brain Injury would not significantly differ in Cognitive Disability - Cognition and Adaptive Behaviour after the Cognitive Skill Development Training” is rejected.

\section{DISCUSSION}

Cognitive skill development Training improved Cognition and Adaptive Behavior among People with Traumatic Brain Injury.

Cognitive Skill Development Training showed significant improvement in sub-average cognitive functioning and adaptive behavior which affects day to day performance of People with Mild Traumatic Brain injury. It has consistently improved higher reasoning, thoughtfulness, learning, concentration, intelligence, and other mental functions. Blazquez et al., (2016) studied Cognitive deficits, where neuropsychological evaluation showed some difficulties, related to attention, working memory and executive functions. The strengthening of processes related to attention control and executive functions give their support to the learning of compensatory approaches and those functions needed for perceptual abilities. Londos et al., (2008) studied the effects of a goal-oriented rehabilitation program in mild cognitive impairment. The study evaluated if a recognized rehabilitation program commonly used in Traumatic Brain Injury would support Mild Cognitive Impaired patients to develop compensatory memory techniques improve their cognition, occupational performance and quality of life. The study concluded significant improvements were seen in cognitive processing speed, occupational performance and in some of the Quality of life domains. Kim et al., (2006) conducted a study to develop a comprehensive cognitive rehabilitation program that can be easily applied to People with Traumatic Brain Injury. The memory rehabilitation programs mainly comprised of mnemonic skills, which helps them memorize given information by linking together common attributes, visual imagery and self-instruction method. Bouwens et al., (2009) examined the feasibility of and clinical experiences for the evaluation of cognitive rehabilitation in people with acquired brain injury.

Cognitive Skill Development Training was conducted to tap the innate potentiality of People with Mild Traumatic Brain injury. Cognitive Skill Development Training was specially scheduled by the investigator in accordance with the problems encountered by them. 


\section{Cognitive Skill Development Training for People with Traumatic Brain Injury}

Cognitive development games were administered on them under this training program mainly to enhance cognitive skill and modify their behaviour. While a precise definition of executive functioning is elusive, it is generally accepted that it is high level cognitive functioning that includes the control and regulation of all aspects of deliberate, non-automatic, and nonroutine behaviour. Executive functioning comprises of formulation of goals, planning, and carrying out the drafted plans, also revising those plans in response to feedback which includes, observing, assessing, and thinking deliberately and flexibly, by adopting moral and ethical behaviour. Behaviour problems gradually become worse after sustaining a Traumatic Brain Injury. Factors contributed include a combination of neurological affective disturbances and reactions to negative environmental influences. People with Traumatic Brain Injury exhibit increased disturbances in novel memory, emotional liability and motivational problems. Cognitive Skill Development Training which consisted of game modules gradually improved observation ability of People with Mild Traumatic Brain injury, guided them to discover observation techniques and principles which strengthen their concentration ability through playing relative games of matching items by observing features of appearance, combinations, sequences of colours, shapes and quantities of items. This activity also develops their logical thinking and reasoning abilities, train up differentiating positions, directions, comparing sizes and tracing routes. These activities help to develop their logical reasoning, sequencing abilities and examine their general knowledge and perceptions through games of reasoning. It also deepens their common knowledge about the general characteristics, living habits and environments of different animals and insects by different matching games. It improved their ability to categorize things by observing items and by applying their general knowledge. It also developed general knowledge perception about specific things and featured items that relate to different seasons and months in a year. The problem solving technique, one among Cognitive Skill Development Training included a task of games or plays which stimulated People with Traumatic Brain Injury's curiosity and interest. The training on problem solving technique was to encourage the process of deriving reasonable solutions for a problematic situation resembling real problems that the patients encounter in everyday life. Hence, Cognitive Skill Development Training could help people having difficulty in their daily life, due to decreased cognitive ability resulting from brain injury.

\section{CONCLUSION}

Cognitive skill Development Training improved Cognition and Adaptive Behavior among People with Mild Traumatic Brain Injury. The study has implications for Rehabilitation therapist and Counsellors in identifying problems and to help them cope better and prevent more serious complications.

\section{SUGGESTIONS}

1. Other Cognitive factors like thinking, reasoning, problem solving can be studied.

2. People with moderate and severe Traumatic Brain Injury with cognitive deficits can be chosen for further research.

3. The size of the sample may be increased. 


\section{Cognitive Skill Development Training for People with Traumatic Brain Injury}

4. People with Mild Traumatic Brain Injury with cognitive deficits in rural and semi urban areas can be researched.

5. Follow up study after the post test, to assess the effectiveness of Cognitive Skill Development Training can be conducted.

\section{IMPLICATIONS}

1. Improves the performance of People with Mild Traumatic Brain Injury in everyday cognitive tasks.

2. Impacts People with Mild Traumatic Brain Injury in basic skill and social skills.

3. Enhances their ability to process and interpret information.

4. Improves their ability to perform mental functions.

5. Reinforces, strengthens and restores the impaired skills.

6. Bypasses and compensates for the impaired function.

\section{LIMITATIONS OF THE STUDY}

1. Cognitive Disability only in relation to cognition and adaptive behavior is studied.

2. People with Mild Traumatic Brain Injury with cognitive deficits were chosen for the study.

3. The sample size of the study is restricted to 90 .

4. The geographical location of the present study is confined to Chennai City.

5. Follow up study after the post-test to assess the effectiveness of Cognitive skill development training is not conducted.

\section{Acknowledgments}

The author appreciates all those who participated in the study and helped to facilitate the Research process.

Conflict of Interests: The author declared no conflict of interests.

\section{REFERENCES}

Ahmed Saeed, Venigalla Hema, Mekala Hema Madhuri, Dar Sara, Hassan Mudasar, Ayub Shahana (2017) Traumatic brain injury and neuropsychiatric complications. https://www.ncbi.nlm.nih.gov/pmc/articles/PMC5385737/

Basford JR, et al. Arch Phys Med Rehabil. (2015) Brief overview and assessment of the role and benefits of cognitive rehabilitation.

https://www.ncbi.nlm.nih.gov/m/pubmed/25757792/

Bouwens SF, et al. Clin Rehabil. (2009) The practical use of goal attainment scaling for people with acquired brain injury who receive cognitive rehabilitation. https://www.ncbi.nlm.nih.gov/m/pubmed/19179354/

Bouwens SF1, van Heugten CM, Verhey FR. (2009) The practical use of goal attainment scaling for people with acquired brain injury who receive cognitive rehabilitation. https://www.ncbi.nlm.nih.gov/pubmed/19179354

Brain Injury Association of America, (1986) Causes of Brain Injury. www.biausa.org

(C) The International Journal of Indian Psychology, ISSN 2348-5396 (e)| ISSN: 2349-3429 (p) | 185 


\section{Cognitive Skill Development Training for People with Traumatic Brain Injury}

Christensen BK1, Colella B, Inness E, Hebert D, Monette G, Bayley M, Green RE. (2008) Recovery of cognitive function after traumatic brain injury: a multilevel modeling analysis of Canadian outcomes. https://www.ncbi.nlm.nih.gov/pubmed/19081439

De Noreña D, et al. Rev Neurol. (2010) Effectiveness of neuropsychological rehabilitation in acquired brain injury (II): Executive functions, behavioural modification and psychotherapy, and the use of the new technologies.

https://www.ncbi.nlm.nih.gov/m/pubmed/21157736/

Finn Orfano, (2012), http://www.brighthubeducation.com/special-ed-learningdisorders/70555-defining-cognitive-disabilities/

Fleminger S (2008) Long-term psychiatric disorders after traumatic brain injury. https://www.ncbi.nlm.nih.gov/pubmed/18289429

Kim YH, Ko MH, Na SY, Park SH, Kim KW. Effects of single-dose methylphenidate on cognitive performance in patients with traumatic brain injury: A double-blind placebo-controlled study. Clin Rehabil. (2006) https://www.ncbi.nlm.nih.gov/pmc/articles/PMC4904751/

Londos E, Boschian K, Lindén A, Persson C, Minthon L, Lexell J. (2008) Effects of a goaloriented rehabilitation program in mild cognitive impairment: a pilot study. https://www.ncbi.nlm.nih.gov/pubmed/18182471

Marina Ávila-Villanueva, Ana Rebollo-Vázquez, José M. Ruiz-Sánchez de León, Meritxell Valentí, , Miguel Medina and Miguel A. Fernández-Blázquez (2016) Clinical Relevance of Specific Cognitive Complaints in Determining Mild Cognitive Impairment from Cognitively Normal States in a Study of Healthy Elderly Controls. file://C:/Users/Praba/Desktop/sonfg/fnagi-08-00233.pdf

Rabinowitz, A. R., \& Levin, H. S. (2014). Cognitive Sequelae of Traumatic Brain Injury. The Psychiatric Clinics of North America, 37(1), 1-11.

http://doi.org/10.1016/j.psc.2013.11.004

Saeed Ahmed, Hema Venigalla, Hema Madhuri Mekala, Sara Dar, Mudasar Hassan, and Shahana Ayub (2017) Traumatic Brain Injury and Neuropsychiatric Complications. https://www.ncbi.nlm.nih.gov/pmc/articles/PMC5385737/

Slomine, B., \& Locascio, G. (2009). Cognitive rehabilitation for children with acquired braininjury. Developmental Disabilities Research Review, 15, 133- 143. doi:10.1002/ddrr.56

Van Heugten C, Gregório GW, Wade D. (2012) Evidence-based cognitive rehabilitation after acquired brain injury: a systematic review of content of treatment. https://www.ncbi.nlm.nih.gov/pubmed/22537117

How to cite this article: Prabha V \& Manickaraj S (2017). Cognitive Skill Development Training for People with Traumatic Brain Injury. International Journal of Indian Psychology, Vol. 5, (1), DIP: 18.01.119/20170501, DOI: 10.25215/0501.119 